\title{
Findings from a Windshield Survey Conducted in an Internally Displaced Community in Nigeria
}

\section{Oluremilekun Comfort Kusimo}

Walden University, Minneapolis, USA

Email: stremi2001@yahoo.com

How to cite this paper: Kusimo, O.C. (2019) Findings from a Windshield Survey Conducted in an Internally Displaced Community in Nigeria. Health, 11, 50-56. https://doi.org/10.4236/health.2019.111006

Received: October 8, 2018

Accepted: January 12, 2019

Published: January 15, 2019

Copyright @ 2019 by author(s) and Scientific Research Publishing Inc. This work is licensed under the Creative Commons Attribution International License (CC BY 4.0).

http://creativecommons.org/licenses/by/4.0/

\begin{abstract}
Introduction: Civil unrest in the north-eastern part of Nigeria has led to displacement of populations and this has resulted in many negative health implications for the displaced persons. Internally displaced persons (IDP) often have poorer health outcomes than the general population due to limited access to health services and other basic amenities. Globally, Nigeria is among the countries with huge health inequalities resulting from unequal access to health services. This contextual issue is reflected in the living conditions of internally displaced populations in the country. A windshield survey was conducted in one of such IDP camps located in Kuchingoro, a central location in the federal capital territory of Nigeria, to describe the living conditions of the occupants and the implication for health outcomes. Objective: This article highlights the health issues faced by the internally displaced persons living in Kuchingoro, Abuja. This population was chosen because of the large size of the IDP camp and its strategic location in the federal capital territory of Nigeria. Conclusion: People living in the IDP camp of Kuchingoro are exposed to myriads of health issues as a result of poor access to clean water, hygiene facilities, foods with nutritional value and health services. The poor sanitary conditions of the camp often result in cholera outbreaks and other health issues. Women, the elderly and the very young are the most vulnerable to poor health outcomes as identified by the survey. Efforts should be made to improve the daily living conditions of the dwellers of the Kuchingoro IDP camp with particular emphasis on water, sanitation and hygiene and the provision of accessible and good quality health services. Government should also ensure the creation of employment opportunities towards empowering the occupants to improve their quality of life.
\end{abstract}

\section{Keywords}

IDP, Kuchingoro, Sanitation, Health Outcomes 


\section{Introduction}

Windshield survey is a scientific and systematic way of observing a community while in a moving vehicle hence the name "windshield" [1]. Observation of a community can also be made while taking a walk through the community [1]. These surveys are useful ways of observing a community in order to have a better understanding of the community and the specific needs or issues that are peculiar to the community [1] [2]. Such needs may include physical, social, economic and medical needs.

A windshield survey was conducted in the internally displaced persons (IDP) camp in New Kuchingoro, a community located within Lugbe in the rural part of Abuja Municipal Area Council (AMAC), Federal Capital Territory (FCT). The community is located behind National Stadium and beside Games Village in Abuja. This report gives a summary of the windshield survey conducted in the IDP camp on the first day of April, 2017. The camp is home to over a thousand occupants. The occupants of the camp are mainly people displaced from the Gwoza community in Borno State because of the unrest caused by the Boko Haram insurgency. Borno State is located in the north-eastern region of Nigeria, therefore most of the occupants of the camp are northerners and Hausa is a common language spoken in the community.

The Kuchingoro IDP camp was considered for a windshield survey because of its large population size and its strategic location in the central part of the federal capital territory of Nigeria, very close to the seat of power. The state of origin of the occupants of Kuchingoro IDP camp is located in the north-eastern part of Nigeria as shown in Figure 1 below.

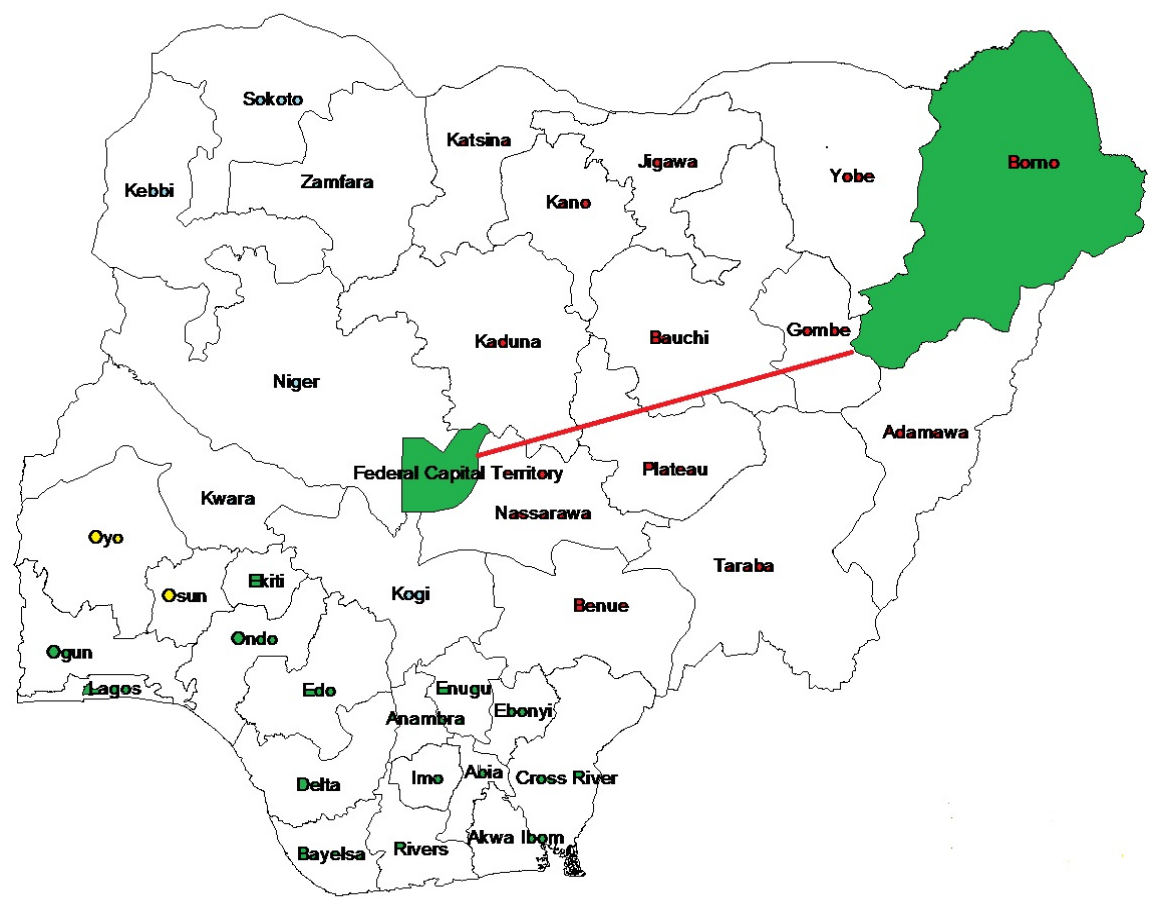

Figure 1. Map showing the origin and new location of the IDP of Kuchingoro. 


\section{Housing and Living Conditions within the Camp}

There are no brick buildings in the camp, the camp is made up of make-shift structures made from cartons, bamboos, empty bags of rice, zinc, tarpaulin, empty bags of cement and other flimsy materials. Each building is home to about seven people, because the space is very small, it becomes crowded with this number of people. There are no drainage structures in the camp and the floor is not cemented or tiled, therefore the place is very dusty because of the open sand. There is only one hygiene facility and one bathroom in the camp, there are no hand wash facilities or modern toilet facilities.

The buildings seen do not seem to follow any layout design and many of them are close together making the camp very crowded. There is a school located in the camp and a NGO that supports the community financially through donations from philanthropists and private organizations. Generally, the standard of living of the people residing in this camp can be considered to be poor. There are no green area or leisure space within the camp, children can however be seen playing in the sand while the older teenagers play ball on the dusty floor. There is only one entrance to the camp and there are no security measures in place to ensure the safety of the occupants of the camp. There are no security guards to man the short gate at the entrance to the camp. Some of the occupants of the camp take turns to man the gate. Criminal issues and major discords are reported to the police station that is close to the camp. There are no landscapes or street signs in the camp. A few NGOs placed their banners within the camp signifying their support to the camp.

Most of the occupants seek healthcare services from chemists and illegal drug sellers that are within the camp. It is apparent from the living conditions in the camp that there is little or no government support to the occupants of the camp which is odd because the state authority started the camp. There is a borehole and a small health clinic in the camp that was provided by NGOs and Christian organizations.

\section{Environment Factors That Indicate a Potential Health Risk}

During the rains, because of the flimsiness of the materials used to build the huts where people live, the roof leaks and the place becomes wet and uncomfortable. Unfortunately, there are no adequate health facilities to cater to the health needs of the occupants of the camp. The people in the camp complain of having very little food to eat most of the time. Once in a while, individuals and NGOs donate food stuffs to the camp but the government has never made such provisions. Some of the people spoken to voiced out their fear of the government demolishing the camp. This fear appears to make them apprehensive of visitors for fear that they may be there to destroy the camp. They stated that they are uncertain of their future. The occupants of the camp are very willing to share their stories in Gwoza and how their lives were changed by the Boko Haram insurgency. 
The camps are covered with many refuse dumps and this makes the camp very smelly and unpleasant in general. One has to move carefully around in order not to step on refuse materials or human wastes. The general poor hygiene condition of the camp makes it prone to outbreaks of infectious disease particularly during the raining season.

The camp is generally noisy and there are often fights and discords among the community members. The fights are usually associated with sharing of food stuffs donated by NGOs and Christian organizations. Poverty is a general issue in the camp, most of the elderly persons in the camp have chronic disease and are unable to access the necessary healthcare needed to manage the chronic disease. The diseases mentioned include diabetes, hypertension and mental health issues. Many of the occupants of the camp were observed to have cough, catarrh and other symptoms of ill-health. A few of the occupants openly complained of abdominal pains, headaches and fever thinking I was one of the representatives of the medical NGOs.

\section{Types of Health Risk That Is Expected When Living, Working, or Playing in This Environment}

From the observations made, there are many children and women in the camp and there are very little economic activities going on in the camp with the exception of buying and selling. Most of the children seen showed signs of malnutrition and stunted growth and many of the women were pregnant.

Due to lack of adequate bathroom facilities in the camp, the occupants of the camp rarely have showers and the smell of sweat and dirt is very apparent when one moves close to them. There are no beauty salons or spas within the camp therefore women are unable to care for their hair and the children have overgrown hair which are infested with head lice.

Generally, the camp is overcrowded and overpopulated with most of the occupants being women and children. Poor access to health services and the poor sanitary condition of the camp makes the community vulnerable to infectious diseases. The camp has witnessed several epidemics in the past and they occur especially during the rainy season. Malaria, diarrhea and tuberculosis are common diseases in the camp. Some of the children given birth to in the camp were not included in the general immunization hence they are prone to vaccine-preventable childhood illnesses such as whooping cough, diphtheria, polio, meningitis amongst others [3]. The use of one toilet facility by all the occupants of the camp exposes them to urinary tract infections as reported by some of the women interacted with during the survey.

Pregnant women are perhaps one of the most vulnerable populations within the camp because they may not have access to antenatal care therefore they may be prone to many pregnancy-related complications. Also, during childbirth, because of sub-optimal access to maternal and child health services, the lives of pregnant women and their babies may be threatened leading to disproportionately high maternally and infant mortality rates within the camp. Additionally, 
children living in this community are mostly malnourished and show signs of stunted growth and failure to thrive because they lack balanced diets and often go for several days without a proper meal [4].

Occupants of the camp may be prone to waterborne diseases such as shigellosis, cholera, hepatitis A and typhoid because of the tendency to drink contaminated water due to lack of hand washing facility and the general poor sanitary condition of the camp [5]. Also, mental health issues may be a common issue in the camp considering the ordeal the occupants of the camp were exposed to in their previous environment and their present poor living conditions [6]. Lack of access to mental healthcare services may translate to escalation of depression and minor mental health issues to major issues such as bipolar disorders, mania and so on [6]. The aged population may not have access to health services to manage existing chronic illnesses therefore their health conditions may further deteriorate and they may become bedridden or die as a result of manageable illnesses. Table 1 below shows the summary of the environmental factors identified during the survey that may impact negatively on the health outcomes of the occupants of the camp.

\section{Persons Identified as Being at Risk in This Environment (e.g., Children, Women, or the Elderly)}

The entire occupants of the camp are at risk of infectious diseases; however women, children and the elderly may be more vulnerable to infectious diseases [7]. This may not be unrelated to gender barriers that make men more likely to be the ones to get the food donated by NGOs and Christian groups while the women and children are considered only after the men have been taken care of. Also, mental health issues may make women vulnerable to physical and verbal

Table 1. Summary of environmental factors \& resulting health issues.

\begin{tabular}{|c|c|c|}
\hline $\mathrm{S} / \mathrm{N}$ & Environmental Factors & Health Issues \\
\hline 1 & Poor drainage system & $\begin{array}{l}\text { Frequent outbreaks of infectious diseases } \\
\text { such as chicken pox, cholera, typhoid etc. }\end{array}$ \\
\hline 2 & $\begin{array}{l}\text { Dirty and crowded } \\
\text { living conditions }\end{array}$ & $\begin{array}{l}\text { Prone to spread of infectious diseases } \\
\text { that are airborne such as } \\
\text { Tuberculosis, measles, influenza etc. }\end{array}$ \\
\hline 3 & $\begin{array}{l}\text { Limited toilet facilities } \\
\text { and lack of clean water }\end{array}$ & $\begin{array}{l}\text { Widespread urinary tract infection } \\
\text { and other WASH-related issues such } \\
\text { as typhoid, malaria, cholera among others }\end{array}$ \\
\hline 4 & Poor security & $\begin{array}{l}\text { Sexual abuse and resulting } \\
\text { STDs and psychological issues }\end{array}$ \\
\hline 5 & $\begin{array}{l}\text { Limited access to health services } \\
\text { including maternal, } \\
\text { neonatal and child health services }\end{array}$ & $\begin{array}{l}\text { Frequent pregnancies and disproportionately high } \\
\text { maternal and infant mortality. Poor management } \\
\text { of chronic diseases such as diabetes, hypertension. }\end{array}$ \\
\hline 6 & Poverty due to unemployment & $\begin{array}{c}\text { Malnutrition, stunted growth and vulnerability to } \\
\text { diseases due to weak immune systems }\end{array}$ \\
\hline
\end{tabular}


abuse by mentally unstable husbands. The crowded living condition and the lack of toilet facilities make women and girls vulnerable to sexual assaults including rapes. Women are also more prone to urinary tract infection because of the anatomy of their urinary organ therefore they are more likely to get infected from using only one toilet facility which is shared by both males and females [8]. Women may also be exposed to sexually transmitted diseases as a result of prevalent sexual molestations that occur in the camp.

The physically disabled and the elderly are prone to physical abuse and because of the poor security measures in place in the camp, hoodlums may steal from them and abuse them physically in the process. Also, lack of access to a proper health facility means that chronic diseases which are most common among the elderly cannot be managed adequately. Children are the most vulnerable in this community because of the tendency for them to be malnourished and unprotected from vaccine-preventable childhood illnesses [3] [4].

\section{Conclusion}

In general, the people living in the IDP camp of Kuchingoro are exposed to myriads of health issues as a result of poor access to clean water and hygiene facilities. The poor sanitary conditions of the camp often result in cholera outbreaks and other health issues. Also, lack of income opportunities means that poverty is a constant reality to the occupants of the camp. This translates to malnutrition and a generally poor quality of life. Women, the elderly and the very young are the most vulnerable to poor health outcomes as identified by the survey. Efforts should be made to improve the daily living conditions of the dwellers of the Kuchingoro IDP camp with particular emphasis on water, sanitation and hygiene and the provision of accessible and qualitative health services. Health services should be prioritized for women, children and the elderly while ensuring universal health coverage for all. Government should also ensure the creation of employment opportunities towards empowering the occupants to improve their quality of life.

\section{Conflicts of Interest}

The author declares no conflicts of interest regarding the publication of this paper.

\section{References}

[1] Laureate Education (Producer) (2012) Needs Assessment: Conducting a Windshield Survey. Laureate Education (Producer), Baltimore, MD.

[2] Callan, L.B. (1971) Adapting the Windshield Survey Model to Community Health Education. HSMHA Health Reports, 86, 202-203. https://doi.org/10.2307/4594130

[3] Lam, E., McCarthy, A. and Brennan, M. (2015) Vaccine-Preventable Diseases in Humanitarian Emergencies among Refugee and Internally-Displaced Populations. Human vaccines \& immunotherapeutics, 11, 2627-2636. https://doi.org/10.1080/21645515.2015.1096457 
[4] Olwedo, M.A., Mworozi, E., Bachou, H. and Orach, C.G. (2008) Factors Associated with Malnutrition among Children in Internally Displaced Person's Camps, Northern Uganda. African Health Sciences, 8, 244-252.

[5] Owoaje, E.T., Uchendu, O.C, Ajayi, T.O. and Cadmus, E.O. (2016) A Review of the Health Problems of the Internally Displaced Persons in Africa. Nigerian Postgraduate Medical Journal, 23, 161-171. https://doi.org/10.4103/1117-1936.196242

[6] Kim, G., Torbay, R. and Lawry, L. (2007) Basic Health, Women's Health, and Mental Health among Internally Displaced Persons in Nyala Province, South Darfur, Sudan. American Journal of Public Health, 97, 353-361. https://doi.org/10.2105/AJPH.2005.073635

[7] Bile, K.M., Hafeez, A., Kazi, G.N. and Southall, D. (2011) Protecting the Right to Health of Internally Displaced Mothers and Children: The Imperative of Inter-Cluster Coordination for Translating Best Practices into Effective Participatory Action. Eastern Mediterranean Health Journal, 17, 981-989.

https://doi.org/10.26719/2011.17.12.981

[8] Wasay, M. and Mushtaq, K. (2010) Health Issues of Internally Displaced Persons in Pakistan: Preparation for Disasters in Future. American Journal of Disaster Medicine, 5, 126-128. https://doi.org/10.5055/ajdm.2010.0014 